\title{
2020 Microscopy Today Micrograph Awards
}

\begin{abstract}
Competition finalists shown on the cover are identified below. The identity and affiliation of the submitters were not known to the judges. The larger number of Open category finalists reflects the larger number of entries in that category. Prize winners will be named in the Microscopy Today section of the awards presentation at the virtual M\&M meeting in August. Finalist micrographs may be viewed at the 2020 gallery (see website at the bottom of this page). The microscopy community may vote for the People's Choice Award at the same website.
\end{abstract}

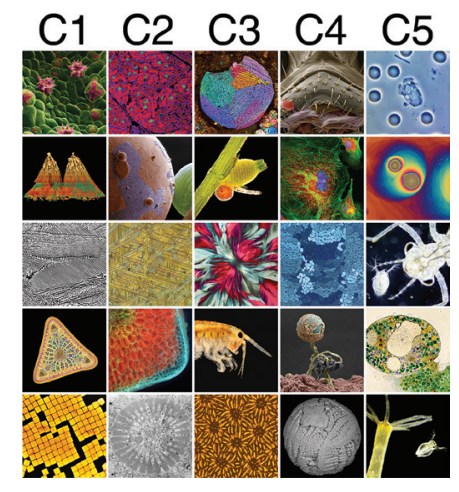

\section{Column 1 (Published category)}

C1-1 Calcium oxalate druses in intercellular spaces of a lotus leaf (SEM SE/BSE) by Hans Ensikat

C1-2 Native vanadium dendrites in hibonite (X-ray microscopy tomogram) by Sarah Gain

C1-3 $\quad \mathrm{LaPO}_{4} / \mathrm{Al}_{2} \mathrm{O}_{3}$ eutectic microstructure produced by flash sintering (SEM BSE) by Yingjie Yang

C1-4 Triceratium morlandii diatom from a prep by H.J. Baker (phase contrast LM) by Larry Gouliard, Jr.

C1-5 Gold nanocubes with monodispersed size distribution (SEM SE) by Vasile-Dan Hondoroaba

\section{Columns 2, 3, and 4 (Open category of unpublished micrographs)}

C2-1 Fetal bovine muscle tissue sectioned and decorated with antibodies (confocal LM) by Rhonda Powell

C2-2 Ejected particles from the deposition of an Al composite material (SEM SE) by Michael Baughman

C2-3 Needle-shaped martensite in an FeCoCrMn high entropy alloy (reflected LM) by Mainak Saha

C2-4 Aloe vera leaf slice imaged using a halogen lamp to excite fluorescence (LM) by Jose Martinez-Lopez

C2-5 Zosterograptus sp. showing microtubules the protozoan uses for feeding (TEM) by Andrea Brothers

C3-1 Barred olivine in chondrule of a chondrite meteorite thin section (polarized LM) by Bernardo Cesare

C3-2 Chara sp. green alga filament with reproduction organs (dark field LM) by Gerd Günther

C3-3 Thin film crystals formed from a solution containing Fe, Al, and P sulfates (polarized LM) by Karl Gaff

C3-4 Freshwater amphipod photographed in water (dark field LM) by Michael Much

C3-5 Cuticle of the mite Labidostomma luteum collected in a primeval forest (SEM) by Zbigniew Adamski

C4-1 Rove beetle Aleochara sp. showing frontal view of mouth area (SEM SE) by Igor Orlov

C4-2 Rat endothelial cells marked with fluorescent dyes (epifluorescence LM) by Damon Strom

C4-3 Grain orientations in an additively manufactured Fe-Nd-B magnet (polarized LM) by Felix Trauter

C4-4 Atlantic Portuguese Man O'War (Physalia physalis) nematocyst capsule (SEM SE) by Connon Thomas

C4-5 Micrometeorite from a Lake Michigan sediment core (SEM BSE) by Anette von der Handt

\section{Column 5 (Video category)}

C5-1 Bacterial phagocytosis by neutrophilic white blood cell (phase contrast LM) by Andrei Savitsky

C5-2 Soap film in motion (bright field LM) by Gerd Günther

C5-3 Damselfly larva eating a ceriodaphnia (dark-field LM) by Andrei Savitsky

C5-4 Dying ciliate (Nassula sp.) expels its organelles and what it has eaten (BF LM) by Julia Van Etten

C5-5 Hydra sp. trying but failing to eat a water flea (dark-field LM) by Julia Van Etten

\section{Vote for your favorite micrograph at the 2020 image gallery: \\ www.microscopy.org/awards/micrograph_gallery.cfm}




\section{Take gallium-free}

\section{microsample preparation}

\section{further}

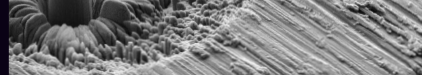

\section{0 .}

Array of micro-compression test pillars in UFG aluminium alloy

\section{TESCAN AMBER $\mathbf{X}$}

$\checkmark$ High throughput, large area FIB milling up to $1 \mathrm{~mm}$

$\checkmark$ Ga-free microsample preparation

$\checkmark$ Ultra-high resolution, field-free FE-SEM imaging and analysis

$\checkmark$ In-column SE and BSE detection

$\checkmark$ Spot optimization for high-throughput, multi-modal FIB-SEM tomography

$\checkmark$ Superior field of view for easy navigation

$\checkmark$ Essence $^{\text {Tw }}$ easy-to-use, modular graphical user interface

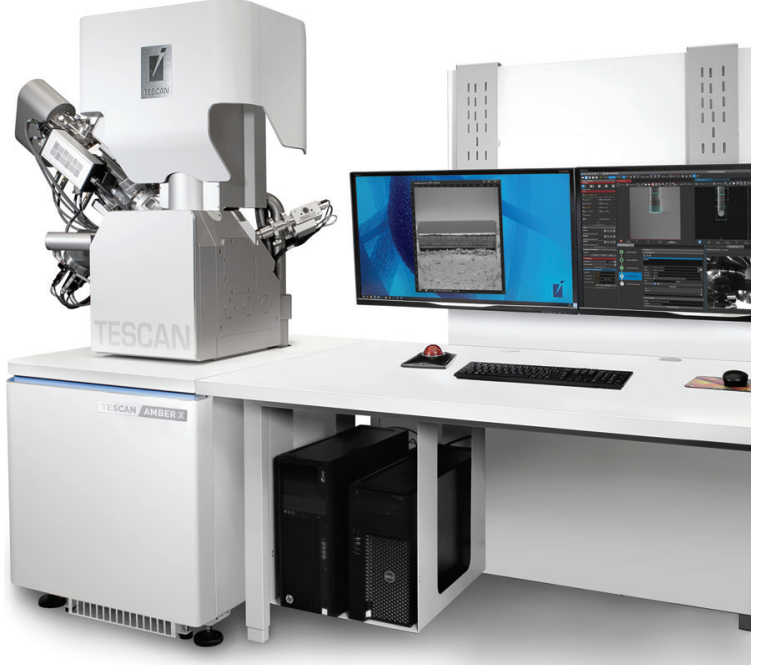

For more information visit 